\title{
Basic ultrasound training assessment in the initial abdominal trauma screening
}

\section{Avaliação de treinamento básico em ultrassom na triagem inicial do trauma abdominal}

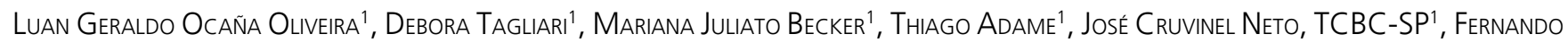
Antônio Campelo Spencer Netto, TCBC-PR ${ }^{1}$

\section{A B S T R A C T}

\begin{abstract}
Objective: to verify the efficiency and usefulness of basic ultrasound training in trauma (FAST - Focused Assessment with Sonography in Trauma) for emergency physicians in the primary evaluation of abdominal trauma. Methods: a longitudinal and observational study was carried out from 2015 to 2017, with 11 emergency physicians from Hospital Universitário do Oeste do Paraná, submitted to ultrasound training in emergency and trauma (USET ${ }^{\circledR}$ - SBAIT). FAST results started to be collected two months after the course. These were compared with a composite score of complementary exams and surgical findings. Information was stored in a Microsoft Excel program database and submitted to statistical analysis. Results: FAST was performed in 120 patients. In the study, 38.4\% of the assessed patients had a shock index $\geq 0.9$. The composite score detected 40 patients with free peritoneal fluid, whereas FAST detected 27 cases. The method sensitivity was $67.5 \%$, specificity was $98.7 \%$, the positive predictive value was $96.4 \%$, the negative predictive value was $85.39 \%$ and accuracy was $88 \%$. All those with a positive FAST had a shock index $\geq 0.9$. Fifteen patients with positive FAST and signs of instability were immediately submitted to surgery. Conclusions: the basic training of emergency physicians in FAST showed efficiency and usefulness in abdominal trauma assessment. Due to its low cost and easy implementation, this modality should be considered as a screening strategy for patients with abdominal trauma in health systems.
\end{abstract}

Descriptors: Ultrasonography. Training/ultrasonics. Multiple Trauma. Abdominal Injuries. Point-of-Care Systems. Advanced Trauma Life Support Care.

\section{INTRODUCTION}

Trin auma is the main cause of mortality and morbidity in Brazil and worldwide, predominantly affecting the population aged $<45$ years $^{1-3}$. Due to its high incidence and years of potential life lost, it constitutes a public health problem, at national and international levels ${ }^{1,3}$.

Aiming to improve the initial screening of trauma patients, more than two decades ago the use of ultrasound (Focused Assessment with Sonography in Trauma - FAST) was incorporated into the initial assessment of trauma victims, under the approval of the American College of Surgeons, through the Advanced Trauma Life Support (ATLS) program ${ }^{1,4-6}$. This evaluation tool resulted in a change in the diagnostic management of multiple trauma patients, replacing the peritoneal lavage method in the assessment of abdominal trauma, particularly in unstable patients ${ }^{4,7,8}$.

Physical examination in multiple trauma patients may be made difficult by the presence of several lesions, as well as the possibility of low level of consciousness level, shock of unknown etiology, central nervous system lesions and other clinical manifestations that make diagnosis difficult at the clinical examination only ${ }^{1}$. FAST consists of a non-invasive ultrasound examination that can be quickly performed by the patient's bedside, aiming to clarify specific clinical issues, regardless of the trauma mechanism that affected the patient $t^{1,3,4,7,8}$. Regarding FAST accuracy in the assessment of abdominal trauma, the sensitivity is $62 \%$ to $94 \%$ and the specificity is greater

1 - Universidade Estadual do Oeste do Paraná, Serviço de Cirurgia Geral, Cascavel, PR, Brasil. 
than $96 \%$ in skilled hands ${ }^{1,4}$.

In this context, FAST has the objective of detecting the presence of free peritoneal fluid (FPF) in the primary assessment of patients victims of acute abdominal trauma ${ }^{1,4}$. The examination is performed in the right upper quadrant (RUQ), called the hepatorenal space or Morrison's pouch, in the left upper quadrant (LUQ) and in presence of free peritoneal fluid $13,3,4,6,7$.

The aim of this study was to verify the efficiency of the basic training in emergency ultrasonography and trauma (USET®), of emergency physicians in the detection of free peritoneal fluid in trauma patients, by measuring the sensitivity, specificity, predictive values, accuracy and likelihood ratios. The method usefulness was assessed by clinical decision-making based on FAST and clinical examination.

\section{METHODS}

The project was approved by the Institutional Research Ethics Committee of Plataforma Brasil under number: 53225215.2.0000.0107. This is a longitudinal, observational study carried out at Hospital Universitário do Oeste do Paraná - HUOP.

With the availability of a LOGIC C5 Premium ultrasound device for the HUOP emergency room in September 2015, the institution provided training to the hospital physicians, with a 10-hour basic course in emergency and trauma ultrasound (USET®) by the Brazilian Society for the Integral Care of Trauma Patients (SBAIT - Sociedade Brasileira de Atendimento Integral ao Traumatizado). This training was voluntary and paid for by the physicians interested in taking it. Eleven emergency physicians (a total of 31 physicians working at emergency at the time) received the training. After the training, the emergency physicians started to use FAST according to its respective indications.

After two months, data on FAST examination performed from 12/2015 to 04/2017 were collected. After FAST performance, the examiners voluntarily notified the authors, through electronic media, allowing an early follow-up of the cases during the study. The inclusion criteria comprised all patients with clinical suspicion of abdominal trauma, blunt or penetrating, submitted to FAST at their initial evaluation.

Additional information was obtained from the patients' physical and electronic medical records. Demographic data (date, identification, gender, age, type of trauma, time since the trauma, vital signs at admission), FAST results (time of exams, ultrasound findings), results of complementary examinations in the abdominal assessment and procedures performed on the patients (laparotomy and its findings) were collected.

FAST reports were compared with a composite score consisting of complementary exams (computed tomography - (T) and clinical and surgical findings. The composite score was used as the gold standard for comparison between the FAST examination results and the evaluation of training efficiency.

The analysis of medical records was used to verify possible changes in clinical or surgical management related to the use of FAST, such as the use of complementary exams or immediate surgery. This criterion was used to assess the method usefulness.

The information was stored in a Microsoft Excel database and submitted to statistical analysis. The results of quantitative and qualitative variables were described by means, absolute values, percentages, predictive values, sensitivity, specificity, accuracy and likelihood ratios. Fisher's exact test was used to verify the strength of associations, as appropriate.

\section{RESULTS}

During the study period, 559 patients with suspected abdominal trauma were admitted and FAST was performed in 120 patients. The patients' mean age was 35 years, with a prevalence of males. Most received prehospital care and there was a greater prevalence of blunt trauma (Table 1). Three patients were excluded from the analysis, as they had inconclusive tests (two patients identified as obese). 
Table 1. Demographic data of the total number of patients assessed in the study.

\begin{tabular}{cc}
\hline Variable & Values \\
\hline Mean age (years) & 35.6 \\
Male gender (\%) & 75.6 \\
Prehospital care (\%) & 94 \\
Tachycardia * (\%) & 30 \\
$\mathrm{BP}<70 \mathrm{mmHg} * *(\%)$ & 22 \\
Blunt trauma (\%) & 74.2 \\
SI*** $\geq 0.9(\%)$ & 37.5
\end{tabular}

*Tachycardia: HR>100 beats/min; **BP: Blood pressure ${ }^{* * * S I: ~ S h o c k ~}$ index.

The composite score (CS) detected 40 patients with free peritoneal fluid (FPF) according to the following distribution of detection methods: CT: 17; CT + surgery: 8; surgery: 15. FAST detected 27 cases of FPF. Among these, one patient with blunt trauma had a false positive (FP) case.

When reviewing the abdominal $\mathrm{CT}$, nine patients had less than $400 \mathrm{~mL}$ of free fluid in the peritoneal cavity, all of them negative by FAST. The values obtained by the USET ${ }^{\circledR}$ of sensitivity, specificity, positive predictive value (PPV), negative predictive value (NPV), accuracy $(A)$, positive likelihood ratio (PLR) and negative likelihood ratio (NLR) for all patients with FPF and for those with a significant amount of free peritoneal fluid (SAFPF $>400 \mathrm{~mL}$ ) are shown in table 2 .

Table 2. Association of FAST in the assessment of all patients with free peritoneal fluid (FPF) $x$ significant amount of FPF (SAFPF)

\begin{tabular}{ccc}
\hline Variable & All FPF & SAFPF \\
\hline Sensitivity & 67.5 & 87 \\
Specificity & 98.7 & 98.8 \\
Accuracy & 88 & 95.7 \\
Positive predictive value & 96.4 & 96.4 \\
Negative predictive value & 85.4 & 95.5 \\
PLR $^{*}$ & 49.7 & 72.5 \\
NLR $^{*}$ & 0.33 & 0.1 \\
\hline
\end{tabular}

*PLR: Positive Likelihood Ratio; **NLR: Negative Likelihood Ratio.

Forty-five patients (38.4\%) had a shock index ${ }^{9}$ (SI) $\geq 0.9$ on admission. All patients (27) with a positive FAST had $\mathrm{SI} \geq 0.9$. There was an association between $\mathrm{SI} \geq 0.9$ and the presence of positive CS or positive FAST (both $\mathrm{p}<0.0001$ ). Fifteen patients, of 27 with positive FAST and $\mathrm{SI} \geq 0.9$, were immediately submitted to surgery for bleeding treatment, without undergoing additional tests.

All patients with positive FAST (27) underwent CT or surgery in comparison to $13(15 \%)$ patients with negative FAST for FPF $(p<0.0001)$.

\section{DISCUSSION}

Trauma is the third cause of death in the Brazilian population and the main one in individuals under 40 years of $\mathrm{age}^{2}$. In the present study, the age group was consistent, with a higher prevalence of blunt trauma and male individuals. The accurate and rapid diagnosis of abdominal bleeding can be difficult, particularly in blunt trauma cases ${ }^{1,4}$. In the present study, it was demonstrated that the training of emergency physicians through a basic ultrasound course and the device availability in the emergency room was sufficient to obtain examinations with sensitivity and specificity values similar to those of skilled professionals ( $>100$ FAST exams $)^{1,4}$. The examination was particularly useful in patients with evidence of FPF (positive FAST) and hemodynamic instability $(I C \geq 0.9)$, allowing the decisionmaking to perform surgery immediately, based on the initial abdominal assessment.

Only $21 \%$ of patients admitted with severe trauma had FAST examination performed at the admission. This may be due to some factors: a) only $1 / 3$ of the attending physicians took the training course and were able to perform the examination; b) our emergency room, as well as several others of the Brazilian Unified Health System (Sistema Único de Saúde do Brasil - SUS), often treats an excessive number of patients, making it difficult to transport the ultrasound device to the bed of the patient that needs to be examined or even the nonavailability of an electrical outlet for the device connection; c) eventual notification failures to the follow-up team regarding the examination performance. However, it could be expected that it would be used in patients with greater possibility of positivity at the initial phase of the method introduction, in this case, unstable patients with evident abdominal trauma. Therefore, a selection bias 
cannot be ruled out for patients with greater possibility of a positive examination. This possible bias does not exclude the method assessment validity, since the hypothesis was tested with a reasonable number of patients, with varied results.

Regarding inconclusive exams, two patients were obese, which made the examination technically unfeasible, and technical difficulty was reported by the professional performing the examination in one patient. The literature reports that the diagnostic performance of FAST depends on several factors, including clinical adjustment, professional skill, equipment and patient condition 1,4,10-12. It is known that obesity is a limiting factor for the ultrasound performance ${ }^{1,4}$. Another bias that may have contributed to the inconclusive results is the fact that most of the errors that occur during the learning period are related to inadequate depth and gain ${ }^{13}$.

Shock index (SI) is an indicator calculated by the ratio of heart rate to systolic blood pressure ( $\mathrm{SI}=\mathrm{HR} /$ SBP) and has been used as a mortality predictor at the admission of a trauma patient, being potentially useful for the identification of patients requiring massive blood transfusion?. Trauma patients with $\mathrm{SI} \geq 0.9$ have a higher mortality and are at higher risk of being submitted to massive blood transfusion ${ }^{9}$. In the present study, $45(38.4 \%)$ of the patients submitted to FAST had a $\mathrm{SI} \geq 0.9$. This demonstrates that more than one third of the patients were potentially severe cases in terms of hemodynamic stability, with a higher mortality rate than patients with a lower SI. All patients with FPF in FAST (27) and 29 (72.5\%) in the CS had a $\mathrm{Cl} \geq 0.9$ at admission, with a strong statistical association. This demonstrates the strong association of abdominal bleeding with hemodynamic instability and suggests the distinct method usefulness in the most severe patients, contributing to the rapid establishment of appropriate therapy for these patients.

The composite score (CS) used in the study consisted of the abdominal $C T$, clinical and surgical findings. This composition represents the choice parameter as a tool for comparison with FAST to obtain predictive values, sensitivity, specificity, accuracy and likelihood ratios. Among the CS variables, the abdominal CT corresponds to the gold standard to detect FPF ${ }^{1,4,6}$.
However, there is limitation of its use in patients with hemodynamic instability due to the treatment urgency of these patients ${ }^{1,4,6}$.

The sensitivity and specificity of FAST for FPF assessment may vary according to the professional's skill from $62 \%$ to $96 \%$ and from $94 \%$ to $99.7 \%$, respectively 4 . The present study demonstrated that, with basic formal training (USET®-SBAIT), in the short term, professionals with little or no experience can obtain results similar to results of previous studies regarding sensitivity and specificity. Therefore, a lower learning curve can be inferred, if compared to studies showing that at least 100 examinations are required to acquire proficiency with the method $^{1,10-12}$. Thus, FAST showed to be a method with a rapid learning curve and easy to use as a propaedeutic tool in the initial assessment of abdominal trauma.

Regarding the limitations of FAST in the assessment of abdominal trauma, loss of sensitivity is possible in cases of pneumoperitoneum, obesity and small amount of FPF $(<400 \mathrm{~mL})^{1}$. Of the 13 false-negative cases, nine were due to small amounts of FPF, detected only by $\mathrm{CT}$. It has been previously demonstrated that FPF $>600 \mathrm{~mL}$ is easily observable on FAST examination. The detection of amounts between $400 \mathrm{~mL}$ and $600 \mathrm{~mL}$ depends on the professional's skill and values below $400 \mathrm{~mL}$ are difficult to visualize ${ }^{1,4}$. In this context, if we disregard these nine patients with a small amount of FPF, the sensitivity of FAST increases from $67.5 \%$ to $87 \%$ and the accuracy from $88 \%$ to $95.7 \%$. In general, patients with $F P F<400 \mathrm{~mL}$ do not have an indication for emergency surgical intervention and show good evolution when submitted to non-surgical treatment ${ }^{1}$. In this study, all patients with a small amount of FPF in the CT evaluation received conservative management and showed good evolution.

FAST is a rapid, low-cost examination that can result in valuable prognostic information in patients who are hemodynamically stable or not ${ }^{14,15}$. Therefore, in hemodynamically stable patients, the method is potentially useful both for the initial screening and to rationalize the use of health resources, reducing the number of requested abdominal CTs and potentially avoiding a hospital transfer for specialized assessment ${ }^{14,15}$. In the present study, there was a statistically significant 
reduction in the use of abdominal $\mathrm{CT}$ in patients with negative FAST. Although the test result may have influenced this decision, it is likely that other conditions such as the trauma mechanism and clinical conditions have influenced this decision. However, in a developing country such as Brazil, with a low availability of resources in the SUS (Sistema Único de Saúde, in English: Unified Health System) health units, FAST can be a potentially useful tool to facilitate patient screening and rationalize the use of resources in trauma patients.

In cases of hemodynamic instability, FAST can quickly identify FPF and, consequently, reduce the time of referral for emergency surgery ${ }^{15}$. In this study, 15 patients had this benefit, being submitted to emergency laparotomy soon after the positive FAST, confirming the abdominal location of the bleeding.

Since FAST is a relatively simple, fast, lowcost examination with a short learning curve, the basic training of professionals and the availability of ultrasound equipment to assess acute abdominal trauma can have a positive impact on the treatment and survival of trauma patients. This examination can help in therapeutic decision-making in patients who: a) require immediate surgical intervention (unstable with positive FAST); b) require urgent investigation to detect another reason for the shock (unstable with negative FAST); c) require further evaluation through complementary tests (stable with positive FAST); d) have indication of clinical observation and serial evaluations (stable with negative FAST). Its systematic use in the care of trauma patients can rationalize and reduce the use of human and material resources in health systems, in addition to providing early and significant information to physicians, which will potentially reduce the risk of complications and deaths in this group of patients.

Therefore, the basic training in emergency and trauma ultrasound administered to emergency physicians with no previous experience with the method, demonstrated to be efficient in their training to perform FAST in the initial screening of abdominal trauma, considering the obtained results with moderate sensitivity, high accuracy and high specificity. The method was particularly useful for trauma patients with evidence of hemodynamic instability and positive FAST, allowing immediate access to surgical treatment. The training simplicity and FAST applicability suggest that the universalization of FAST access in health systems can lead to the rationalization of resource utilization, as well as improvement of clinical outcomes in trauma patients.

\title{
R E S U M O
}

\begin{abstract}
Objetivo: verificar a eficiência e a utilidade do treinamento básico em ultrassom no trauma (Focused Assessment with Sonography in Trauma - FAST) para emergencistas, na avaliação primária do trauma abdominal. Métodos: estudo longitudinal, observacional, realizado durante o período de 2015 a 2017, com 11 emergencistas do Hospital Universitário do Oeste do Paraná, submetidos ao treinamento em ultrassom na emergência e trauma (USET ${ }^{\circledR}$ - SBAIT). Resultados dos FAST começaram ser coletados dois meses após o curso. Estes foram comparados com escore composto de exames complementares e achados cirúrgicos. Informações foram armazenadas em banco de dados do programa Microsoft Exce/® e submetidas à análise estatística. Resultados: foram realizados FAST em 120 pacientes. No estudo, 38,4\% dos pacientes avaliados apresentavam índice de choque $\geq 0,9$. O escore composto detectou 40 pacientes com líquido livre peritoneal. FAST detectou 27 casos de líquido livre peritoneal. A sensibilidade do método foi de 67,5\%, a especificidade de 98,7\%, o valor preditivo positivo de $96,4 \%$, o valor preditivo negativo de $85,39 \%$ e a acurácia foi de $88 \%$. Todos que tiveram FAST positivo apresentavam índice de choque $\geq 0,9$. Quinze pacientes com FAST positivo e sinais de instabilidade foram conduzidos imediatamente para cirurgia. Conclusões: o treinamento básico de emergencistas em FAST demonstrou eficiência e utilidade mediata na avaliação do trauma abdominal. Por seu baixo custo e facilidade de implantação, esta modalidade deve ser considerada como estratégia de triagem de pacientes com trauma abdominal nos sistemas de saúde.
\end{abstract}

Descritores: Ultrassonografia. Capacitação/ultrassom. Traumatismo Múltiplo. Traumatismos Abdominais. Sistemas Automatizados de Assistência Junto ao Leito. Cuidados de Suporte Avançado de Vida no Trauma. 


\section{REFERENCES}

1. Williams SR, Perera P, Gharahbaghian L. The FAST and E-FAST in 2013: trauma ultrasonography: overview, practical techniques, controversies, and new frontiers. Crit Care Clin. 2014;30(1):119-50.

2. Brasil. Ministério da Saúde. Datasus. Indicadores de Saúde. [Internet]. [acessado em 05 set 2017]. Disponível em: http://tabnet.datasus.gov.br/cgi/ tabcgi.exe?sim/cnv/ext10uf.def.

3. Flato UAP, Guimarães HP, Lopes RD, Valiatti JL, Flato EMS, Lorenzo RG. Utilização do FAST-Estendido (EFAST-Extended Focused Assessment with Sonography for Trauma) em terapia intensiva. Rev Bras Ter Intensiva. 2010;22(3):291-9.

4. Savatmongkorngul S, Wongwaisayawan S, Kaewlai R. Focused assessment with sonography for trauma: current perspectives. Open Access Emerg Med. 2017;9:57-62.

5. American College of Surgeons. ATLS: Advanced Trauma Life Support: student course manual. 9th ed. Chicago (IL): American College of Surgeons; 2012.

6. Richards JR, McGahan JP. Focused Assessment with Sonography in Trauma (FAST) in 2017: what radiologists can learn. Radiology. 2017;283(1):30-48.

7. Wongwaisayawan $S$, Suwannanon R, Prachanukool T, Sricharoen P, Saksobhavivat N, Kaewlai R. Trauma ultrasound. Ultrasound Med Biol. 2015;41(10):2543-61.

8. Ghafouri HB, Zare M, Bazrafshan A, Modirian E, Farahmand S, Abazarian N. Diagnostic accuracy of emergency-performed focused assessment with sonography for trauma (FAST) in blunt abdominal trauma. Electronic Physician. 2016;8(9):2950-3.

9. Allgöwer M, Burri C. ["Shock-index"]. Dtsch Med Wochenschr [Internet]. 1967;92(43):1947-50. [cited 2017 set 12]. Available from: https://www.mdcalc. com/shock-index\#evidence. German.

10. Blehar DJ, Barton B, Gaspari RJ. Learning curves in emergency ultrasound education. Acad Emerg Med.
2015;2(5):574-82.

11. Ziesmann MT, Park J, Unger BJ, Kirkpatrick AW, Vergis A, Logsetty $S$, et al. Validation of the quality of ultrasound imaging and competence (QUICK) score as an objective assessment tool for the FAST examination. J Trauma Acute Care Surg. 2015;78(5):1008-13.

12. Ziesmann MT, Park J, Unger B, Kirkpatrick AW, Vergis A, Pham C, et al. Validation of hand motion analysis as an objective assessment tool for the Focused Assessment with Sonography for Trauma examination. J Trauma Acute Care Surg. 2015;79(4):631-7.

13. Jang $T$, Kryder $G$, Sineff $S$, Naunheim R, Aubin C, Kaji AH. The technical errors of physicians learning to perform focused assessment with sonography in trauma. Acad Emerg Med. 2012;19(1):98-101.

14. Dammers D, El Moumni M, Hoogland II, Veeger $\mathrm{N}$, ter Avest E. Should we perform a FAST exam in haemodynamically stable patients presenting after blunt abdominal injury: a retrospective cohort study. Scan J Trauma Resusc Emerg Med. 2017;25(1):1. doi: 10.1186/s13049-016-0342-0.

15. Lane BH. Evidence for cost-effectiveness of ultrasound in evaluation of blunt trauma patients. Emerg Care J. 2016;12(2):63-6.

Received in: 07/08/2017

Accepted for publication: 02/11/2017

Conflict of interest: none.

Source of funding: none.

\section{Mailing address:}

Luan Geraldo Ocaña Oliveira

E-mail: luan_gocana@hotmail.com /

luangocanadeoliveira@gmail.com

\section{(cc) BY}

